\title{
Breathing Synchronised Hypoglossal Nerve Stimulation with Inspire for Untreated Severe Obstructive Sleep Apnoea/Hypopnoea Syndrome: A Simulated Cost-Utility Analysis from a National Health Service Perspective
}

\author{
Deirdre B. Blissett ${ }^{1}\left[\right.$ ] Joerg S. Steier ${ }^{2,3} \cdot$ Yakubu G. Karagama $^{3} \cdot$ Rob S. Blissett $^{1}$
}

Accepted: 12 April 2021 / Published online: 28 April 2021

(c) The Author(s) 2021

\begin{abstract}
Background Hypoglossal nerve stimulation (HNS) with Inspire is a novel treatment indicated for moderate or severe obstructive sleep apnoea/hypopnoea syndrome (OSAHS), intolerant to or unable to be treated with continuous positive airway pressure (CPAP).

Objective The aim of this study was to assess the cost effectiveness of treating moderate or severe OSAHS, in patients intolerant to CPAP, with HNS, compared with standard care, from a National Health Service (NHS) perspective.

Methods A cohort state transition model was developed to compare HNS with Inspire with no treatment in UK adult patients with moderate or severe OSAHS who have previously tried and have not responded to CPAP therapy. Published literature was applied in the model to estimate incremental cost-effectiveness ratios (ICERs; 2019 Great British pounds per qualityadjusted life-year [QALY] gained), from an NHS and personal social services (PSS) perspective, over a cohort's lifetime. Results The model base-case predicts that patients undergoing HNS will incur lifetime costs of $£ 65,026$ compared with $£ 36,727$ among untreated patients. The HNS cohort would gain 12.72 QALYs compared with 11.15 QALYs in the notreatment arm. The ICER of treating severe OSAHS with HNS is therefore estimated to be $£ 17,989$ per QALYs gained. Probabilistic sensitivity analysis found that at a threshold of $£ 30,000 / \mathrm{QALY}$, HNS has a $69 \%$ probability of being cost effective. Limitations of the model include uncertainty around the utility data that were not sourced directly from HNS clinical trials. There is further uncertainty in the relationship between change in the Apnoea-Hypopnoea Index (AHI) and reduction in ischaemic heart disease and stroke because of difficulty capturing the reduction in risk over a long time horizon in studies. Conclusions Over a patient's lifetime, HNS with Inspire is expected to be cost effective when compared with no treatment in patients with severe OSAHS who have tried and have not responded to CPAP, from an NHS perspective.
\end{abstract}

Deirdre B. Blissett

Deirdre.blissett@medtecheconomics.co.uk

1 MedTech Economics, 14 Marnhull Rise, Winchester SO22 5FH, UK

2 Guy's and St Thomas' NHS Foundation Trust, London, UK

3 Faculty of Life Sciences and Medicine, CHAPS, King's Cllege London, London, UK

\section{Key Points for Decision Makers}

The model predicts that patients undergoing hypoglossal nerve stimulation (HNS) will incur lifetime costs of $£ 65,026$ and gain 12.72 quality-adjusted life-years (QALYs) compared with a cost of $£ 36,727$ and gains of 11.15 QALYs among untreated patients.

Over a patient's lifetime, HNS with Inspire is therefore expected to result in an incremental cost-effectiveness ratio of $£ 17,989$ per QALY gained when compared with no treatment in patients with severe obstructive sleep apnoea/hypopnoea syndrome who have tried and failed continuous positive airway pressure. 


\section{Introduction}

Obstructive sleep apnoea/hypopnoea syndrome (OSAHS) is a common and serious condition. Symptomatic OSAHS is estimated to be prevalent in $10 \%$ of 30 - to 49 -year-old males and $3 \%$ of 30 - to 49 -year-old females, rising to $17 \%$ of 50- to 70-year-old males and 9\% of 50- to 70-year-old females [1]. OSAHS is characterised by repeated episodes of apnoea during sleep, caused by the narrowing or closure of the pharyngeal airway, the result of which causes the body to wake in response as the brain and body become oxygen deprived $[2,3]$. Untreated OSAHS has a significant impact on patients' quality of life (QoL) $[4,5]$. Night symptoms include loud snoring, laboured breathing and gasping, frequent awakenings, dry mouth and frequent nocturia, while daytime symptoms include excessive daytime sleepiness (EDS), irritability, decreased concentration, memory impairment, decreased energy and depression [3].

Untreated OSAHS is associated with high morbidity due to increased risk of hypertension, coronary artery disease, congestive heart failure, arrhythmias and stroke. Patients with untreated moderate and severe symptoms of OSAHS have higher blood pressure, with systolic and diastolic blood pressure reducing with successful treatment [6]. Successful treatment is estimated to improve overall survival by $14 \%$ after 14 years [7, 8]. Furthermore, untreated OSAHS is associated with a threefold higher risk of road traffic accidents (RTAs) compared with treated patients experiencing severe EDS [9]. In addition to higher healthcare costs from increased risk of ischaemic heart disease (IHD), stroke and RTAs, healthcare resource utilisation costs are reported to be $19 \%$ higher in untreated OSAHS prior to the diagnosis and initiation of treatment [10].

Continuous positive airway pressure (CPAP), a medical device that delivers a continuous supply of pressurised air through a mask, is the standard care treatment for moderate and severe OSAHS in the UK [11]. Mask discomfort, dry mouth and nasal congestion are common adverse effects of CPAP use. Non-adherence or intolerance to CPAP are common and are estimated to range between 34\% [12] and 60\% [13]. Oral devices may be considered for mild or moderate OSAHS but are not recommended for severe OSAHS due to the lack of efficacy. Bilevel positive airway pressure (BiPAP) is sometimes used to treat OSAHS where patients have comorbidities or are morbidly obese [14]. Surgery may be considered in some cases of severe OSAHS with nasal blockage, however no treatments other than CPAP are currently recommended by National Institute for Health and Care Excellence (NICE) for the treatment of moderate or severe OSAHS in the National Health Service (NHS).
Hypoglossal nerve stimulation (HNS) with Inspire uses a novel implantable device developed by Inspire Medical Systems to offer a new treatment option for OSAHS, where CPAP has failed. Treatment is delivered via an implantable device (Inspire HNS implants) that gently stimulates key airway muscles during sleep via the hypoglossal nerve, allowing the patient's airway to remain open [15]. HNS is indicated in patients with moderate to severe OSAHS (Apnoea-Hypopnoea Index [AHI] range from $15-65$ with $<25 \%$ central apnoeas) who are unable to use or get consistent benefit from CPAP, are not significantly obese (body mass index $\leq 32$ ) and are free of complete concentric collapse of the upper airway at the soft palate level [16].

The benefits of HNS with Inspire have been demonstrated in the STAR trial, a multicentre prospective, randomised study in the US and Europe that demonstrated significant improvement in objective and subjective measurements of the severity of OSAHS; 5-year follow-up data show that the effect is maintained over this period [15, 17]. Similar conclusions are reported in a large observational study across three tertiary hospitals in Germany [18], an observational study with parallel control arm design in the US [19] and two retrospective studies on case series [20,21]. High satisfaction rates and improvements in QoL with HNS have also been demonstrated in observational studies [18, 19, 22].

No cost-effectiveness studies of HNS with Inspire have been published from a UK healthcare system perspective. This study therefore assesses the cost effectiveness of treating moderate or severe OSAHS in patients intolerant of CPAP with HNS compared with no treatment (standard care) from an NHS perspective.

\section{Methods}

A cohort state transition Markov model was constructed in Microsoft Excel (Microsoft Corporation, Redmond, WA, USA) to estimate the cost effectiveness of a cohort treated with HNS with Inspire compared with standard care, for which we assumed that in cases where CPAP has been tried and failed, there is effectively no further treatment other than lifestyle advice. Costs are reported in 2019 Great British Pounds (GBP) and are considered from the perspective of NHS England. We adopted a lifetime time horizon, projecting outcomes in qualityadjusted life-years gained (QALYs) over 50 years, and all future costs and outcomes are discounted annually at $3.5 \%$, as is standard practice in health technology appraisals (HTAs) in England [NICE reference case] [23]. We used annual model cycles with half-cycle correction applied. 


\subsection{Patient Population}

A cohort of 10,000 OSAHS patients with severe disease $(\mathrm{AHI}>30)$ was simulated; $84 \%$ were male and the mean age was 55 years as per those enrolled in the STAR clinical trial [15]. This age and sex distribution was expected to reflect those seeking treatment for severe OSAHS, where the prevalence is higher in males and in older age groups [1]. A similar demographic was enrolled in the first realworld study of HNS with Inspire [24].

\subsection{Model Structure}

The model diagram, illustrated in Fig. 1, comprises a similar structure to prior health economic models in OSAHS [25-27], also using a state transition structure to track costs and outcomes after obstructive sleep apnoea (OSA)-related events. The model structure was selected because OSASH is a chronic condition where healthcare costs are incurred over time, and to track differences in costs and QALYs after OSA-related events. There are three alive health statesOSAHS, post-IHD and post-stroke-as well as an absorbing death state. Patients enter the model in an OSAHS health state and may move to any of the three alive states during the model cycle. The transition probabilities are derived from the individual risks of possible events that make up the possible pathway from one state to another. For stroke, IHD, and all-cause mortality events, the risk depends on a patient's age. Within each alive health state, there is also a risk of a non-fatal RTA event that does not trigger a transition to another health state but does capture the cost and disutility of the event. The post-stroke health state incorporates all functional status outcomes defined by a patient's modified Rankin score (mRS), a measure of stroke severity; an average of the costs and utilities, weighted by mRS distribution, are applied in this state.

\subsection{Assumptions}

Patients in the HNS arm are assumed to have improved to mild disease because both clinical trial [17] and real-world evidence $[24,35]$ demonstrate a reduction of obstructions, resulting in an AHI of $<15$ events/h, with stimulation. Furthermore, it is assumed that by reducing the AHI with HNS, the same benefits in reduced cardiovascular disease (CVD) risk would be experienced as observational studies have suggested [28]. The age-specific stroke and IHD fatality rates in the untreated arm are adjusted using the hazard ratios (HRs) for severe and mild OSAHS. This implies a structural assumption that effective treatment of severe OSAHS, defined as reducing OSAHS severity from severe to mild, as measured by AHI, reduces the higher risk of CVD associated with severe OSAHS. No transition between IHD and stroke is allowed to occur. Although this is unlikely to be clinically true, it will have little impact on the incremental results as the same is the case for both arms. A 50-year time horizon was selected to capture lifetime costs and utility because the treatment effect is expected to be maintained while the implant is in place, assuming that the lifetime of the battery is 11 years, after which it will need to be replaced.
Fig. 1 Schematic representation of the model structure. Four health states are defined, with the events IHD, stroke and death triggering transitions between them. Transition probabilities are calculated as the sum of the individual risks that make up the potential pathway from one event to another. Non-fatal road traffic accident events may occur in the alive health states but do not trigger transitions. $I H D$ ischaemic heart disease, OSAHS obstructive sleep apnoea/hypopnoea syndrome, $P$ probability, $R T A$ road traffic accident

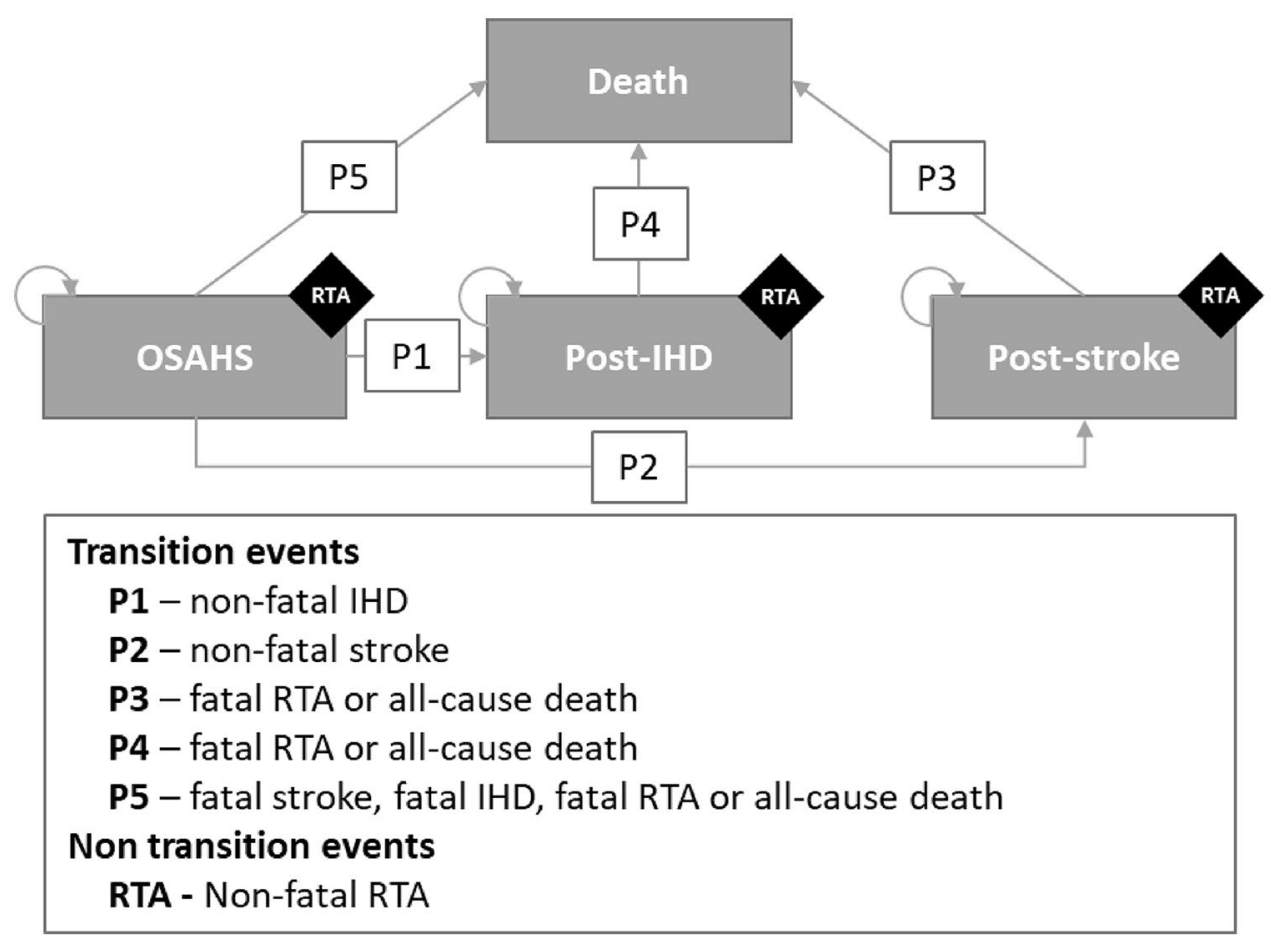




\subsection{Parameter Inputs}

Model inputs are presented in Tables 1, 2 and 3 and are briefly described below.

\subsubsection{Treatment-Related Inputs}

HRs for the increased risk of IHD and stroke events (Table 1) for mild and severe OSAHS were taken from a published meta-analysis of all-cause and cardiovascular mortality in obstructive sleep apnoea that included 27 observational cohort studies that had enrolled a total of 3,162,083 participants [28].

The ratio (Table 1) for increased risk of RTAs was estimated by taking the midpoint of studies identified in a systematic literature review of the burden of daytime sleepiness in OSAHS patients [29]. The risk ratios (RRs) ranged from 1 (no increase in risk) through to 5.1. The patient populations studied were very heterogeneous, therefore no attempt to pool the data was made and the ranges from these studies were used as proxy confidence intervals (CIs) in the probabilistic sensitivity analysis (PSA).

\subsubsection{Epidemiological Inputs}

The baseline incidence of stroke and IHD rates for the UK population were derived from publicly available datasets and published literature (Table 1).

Stroke event rates were calculated by weighting the agespecific rates in a population-based study of nearly 800,000 patients admitted to hospital with acute stroke or who died from stroke in the UK by the proportion of each sex in our target population [30]. Similarly, the age-specific case fatality percentages were weighted by sex to derive the proportion of patients of each stroke event who died.

IHD death rates were derived from the publicly available dataset of IHD deaths compiled by the British Heart Foundation [31]. The age-specific counts of IHD deaths (International Classification of Diseases, Tenth Revision [ICD-10] I20-25) from 2018 were divided by the mid-year population of each age category to estimate age-specific death rates for IHD in the UK. IHD event rates were calculated by estimating the proportion of cases resulting in fatality using agespecific overall incidence rates from the same dataset. For the oldest two age categories, this approach failed to match the two data sources. For the two age bands with missing data, proportions were selected using approximate midpoints between the proportion in the prior age band and $100 \%$; these were tested in sensitivity analysis.

Baseline RTA events were sourced from the Department of Transport (DoT) [32, 34]. Serious, slight, and fatal RTA events were considered in the model and were based on both accidents reported to the police and those estimated to have occurred by the DoT.

Age- and gender-specific baseline mortality rates were sourced from UK life tables and were adjusted to exclude IHD and stroke mortality to avoid double counting, using the methods outlined by Chiang [36].

\subsubsection{Costs}

The model considered health state costs for treated and untreated OSAHS, costs associated with RTAs, IHD and stroke events, and subsequent health states costs and treatment-related costs (Table 2). Where costs were outdated, they were inflated to reflect costs in 2019 using the Consumer Price Index (CPI) for health available from the Office for National Statistics (ONS).

Resource use for treatment with HNS was estimated based on current practice in Germany and the US because, at the time of publication, a limited number of HNS procedures have been performed in UK hospitals. The cost assumptions applied are based on the established care pathway for HNS and are adjusted with NHS reference costs in consultation two UK clinicians. Where available, costs were taken from the NHS National Schedule for NHS Costs 2018/2019 or the prior NHS reference cost schedule. Treatment-related costs included clinical time for two consultant appointments, two sleep studies, a surgical procedure to implant the device, a hospital stay for an outpatient procedure, and the cost of the implant. The procedure time was sourced from an observational study [17] and the hospital stay was assumed to be equivalent to one excess bed day. Training costs were also included, calculated assuming $4 \mathrm{~h}$ of consultant time is required and that each trained consultant would perform 12 surgeries per year. Complications with placing the implant are very rare but occasionally occur, therefore a surgical revision rate was applied that was sourced from an observational study [24]. The cost of surgical revision was assumed to be the equivalent of the initial surgery. The battery for HNS implant with Inspire is expected to be replaced every 11 years. In the absence of any resource use data, the procedure cost of battery replacement is assumed to be $70 \%$ of the original procedure cost for HNS because this would be a faster procedure incurring lower consumable costs.

Health state costs for treated and untreated OSAHS were sourced from an economic evaluation of CPAP for OSAHS in older people (cohort $>60$ ) [37] that reported annual healthcare costs, excluding treatment in a British cohort aged $\geq 65$ years. This source may overestimate costs because this is an older population, or underestimate costs because adherence to CPAP is expected to be lower than HNS. On balance, this source was deemed to be a 
Table 1 Baseline events and clinical effectiveness measures

\begin{tabular}{|c|c|c|c|}
\hline & Input & Distribution & Source \\
\hline \multicolumn{4}{|c|}{ Increased risk of cardiovascular disease in OSAHS patients } \\
\hline Hazard ratio for mild sleep apnoea & 1.24 & $\begin{array}{l}\text { Uniform distribution } \\
\text { Range: lower bound = } 1 \text {; upper bound } \\
\text { is tied to hazard ratio severe sleep } \\
\text { apnoea }\end{array}$ & [28] \\
\hline Hazard ratio for severe sleep apnoea & 2.74 & $\begin{array}{l}\text { Log normal } \\
95 \% \text { CI } 1.94-3.85\end{array}$ & \\
\hline \multicolumn{4}{|c|}{ Increased mortality risk in cardiovascular disease patients } \\
\hline Post-IHD mortality hazard ratio & 3.2 & $\begin{array}{l}\text { Log normal } \\
95 \% \text { CI } 2.67-3.83\end{array}$ & [25] \\
\hline Post-stroke mortality hazard ratio & 2.3 & $\begin{array}{l}\text { Log normal } \\
95 \% \text { CI } 2.00-2.70\end{array}$ & [25] \\
\hline \multicolumn{4}{|c|}{ Increased risk of road traffic events in OSAHS patients } \\
\hline Hazard ratio for mild sleep apnoea & 1.0 & Not varied & Assumption \\
\hline Hazard ratio for severe sleep apnoea & 3.0 & $\begin{array}{l}\text { Log normal } \\
\text { Range } 1.00-6.00\end{array}$ & $\begin{array}{l}\text { Estimate, selecting midpoint in literature review } \\
\text { [29] }\end{array}$ \\
\hline \multicolumn{4}{|c|}{ Baseline risk of stroke events in UK patients (rate per 100,000 person-years) } \\
\hline Event rate in 55- to 64-year-old males & 188.3 & $\begin{array}{l}\text { Log normal } \\
95 \% \text { CI } 183.4-193.2\end{array}$ & {$[30]$} \\
\hline Event rate in 65 - to 74 -year-old males & 462.0 & $\begin{array}{l}\text { Log normal } \\
95 \% \text { CI } 453.0-471.2\end{array}$ & \\
\hline Event rate in 75 - to 84 -year-old males & 1149.5 & $\begin{array}{l}\text { Log normal } \\
95 \% \text { CI } 1130.9-1168.4\end{array}$ & \\
\hline Event rate in $\geq 85$-year-old males & 2416.0 & $\begin{array}{l}\text { Log normal } \\
\text { 95\% CI 2367.7-2465.1 }\end{array}$ & \\
\hline Event rate in 55- to 64-year-old females & 97.8 & $\begin{array}{l}\text { Log normal } \\
95 \% \text { CI } 94.3-101.3\end{array}$ & \\
\hline Event rate in 65 - to 74 -year-old females & 306.5 & $\begin{array}{l}\text { Log normal } \\
95 \% \text { CI } 299.4-313.6\end{array}$ & \\
\hline Event rate in 75 - to 84 -year-old females & 1010.3 & $\begin{array}{l}\text { Log normal } \\
95 \% \text { CI } 995.0-1025.7\end{array}$ & \\
\hline Event rate in $\geq 85$-year-old females & 2602.4 & $\begin{array}{l}\text { Log normal } \\
95 \% \text { CI 2567.3-2637.9 }\end{array}$ & \\
\hline \multicolumn{4}{|c|}{ Baseline risk of IHD deaths in UK patients (rate per 100,000 person-years) } \\
\hline Event rate in 55- to 64-year-old males & 130.9 & Log normal & IHD deaths in 2018 [31] divided by mid-year \\
\hline Event rate in $65-$ to 74 -year-old males & 294.1 & $\mathrm{SE}= \pm 5 \%$ of the mean & population in 2018 in each age category \\
\hline Event rate in 75 - to 84 -year-old males & 695.1 & & \\
\hline Event rate in $\geq 85$-year-old males & 1828.3 & & \\
\hline Event rate in 55- to 64 -year-old females & 36.4 & & \\
\hline Event rate in 65 - to 74 -year-old females & 98.5 & & \\
\hline Event rate in 75 - to 84 -year-old females & 325.2 & & \\
\hline Event rate in $\geq 85$-year-old females & 1045.7 & & \\
\hline
\end{tabular}

close approximation for the difference in healthcare costs with HNS compared with no treatment. No intervention cost was assigned to the standard care arm. In practice, this may include further general practitioner or sleep specialist visits for lifestyle advice. This was not included to avoid any risk of double-counting healthcare costs applied here.

Costs for stroke events and health states were obtained from the Sentinel Stroke National Audit Programme (SSNAP) [38], a UK audit of stroke patients admitted to NHS hospitals. The mean cost of all strokes in men and women in the first and subsequent years were extracted. IHD costs were sourced from a prior health economic evaluation [39], which was selected on the basis that it reported direct medical costs for treating cardiovascular events in a UK population, obtained from a retrospective cohort study using Clinical Practice Research Datalink records from 2006 to 2012. The cost of slight, serious, and fatal RTA events was sourced from the DoT, including only the direct medical costs. 
Table 1 (continued)

\begin{tabular}{|c|c|c|c|}
\hline & Input & Distribution & Source \\
\hline \multicolumn{4}{|c|}{ Case fatality in UK stroke patients (\%) } \\
\hline 55- to 64-year-old males & 12.5 & $\begin{array}{l}\text { Beta } \\
95 \% \text { CI 11.6-13.5 }\end{array}$ & {$[30]$} \\
\hline 65- to 74-year-old males & 17.1 & $\begin{array}{l}\text { Beta } \\
95 \% \text { CI } 16.3-18.0\end{array}$ & \\
\hline 75- to 84-year-old males & 23.4 & $\begin{array}{l}\text { Beta } \\
95 \% \text { CI 22.6-24.2 }\end{array}$ & \\
\hline$\geq 85$-year-old males & 34.3 & $\begin{array}{l}\text { Beta } \\
95 \% \text { CI 33.1-35.5 }\end{array}$ & \\
\hline 55- to 64-year-old females & 15.0 & $\begin{array}{l}\text { Beta } \\
95 \% \text { CI 13.7-16.4 }\end{array}$ & \\
\hline 65- to 74-year-old females & 18.0 & $\begin{array}{l}\text { Beta } \\
95 \% \text { CI 17.0-19.0 }\end{array}$ & \\
\hline 75- to 84-year-old females & 25.9 & $\begin{array}{l}\text { Beta } \\
95 \% \text { CI 25.1-26.6 }\end{array}$ & \\
\hline$\geq 85$-year-old females & 38.3 & $\begin{array}{l}\text { Beta } \\
95 \% \text { CI 37.4-39.1 }\end{array}$ & \\
\hline \multicolumn{4}{|c|}{ Proportion of IHD cases resulting in fatality (\%) } \\
\hline 55- to 64-year-old patients (all) & 21.2 & Not varied & Case fatality is calibrated to match observed \\
\hline 65- to 74-year-old patients (all) & 38.0 & Not varied & overall incidence data [31] \\
\hline 75- to 84-year-old patients (all) & 50.0 & Not varied & Assumption $^{\mathrm{a}}$ \\
\hline$\geq 85$-year-old patients (all) & 75.0 & Not varied & \\
\hline \multicolumn{4}{|c|}{ Road traffic accident event rates in $U K$ drivers } \\
\hline Fatal accidents per year & 1784 & Not varied & {$[32]$} \\
\hline Active drivers in UK & $33,600,000$ & Not varied & {$[33]$} \\
\hline Non-fatal accidents per year & 718,813 & $\begin{array}{l}\text { Log normal } \\
\mathrm{SE}= \pm 25 \% \text { of the mean }\end{array}$ & $\begin{array}{l}\text { Includes slight and serious reported accidents } \\
\text { [32] and estimated non-fatal slight and serious } \\
\text { accidents [34] }\end{array}$ \\
\hline
\end{tabular}

$C I$ confidence interval, $I H D$ ischaemic heart disease, ONS Office for National Statistics, OSAHS obstructive sleep apnoea/hypopnoea syndrome, $S E$ standard error

${ }^{a}$ Assumptions were required because the overall incidence and death rate age categories did not align

\subsubsection{Utilities and Quality-Adjusted Life-Years}

Outcomes are reported in QALYs to capture improved morbidity and mortality associated with effective treatment of OSAHS; we calculated these using published utility estimates (Table 3). Utility values for mild and severe OSAHS were sourced from a US study [44] examining QoL in a clinical sleep disordered breathing (SDB) population assessed using the European Quality of Life-5D (EQ-5D) scale before and after CPAP treatment retrospectively; an assumption is made that treatment with CPAP delivers a utility benefit similar to that expected in a patient who experiences disease improvement from severe to mild. A difference in utility of 0.05 (pre-treatment score 0.765 , post-treatment score 0.815 ) was reported among adherent patients, when patients who reported a QoL measure of 1 before starting CPAP were removed. Utility post stroke was sourced from a QoL study that retrospectively analysed data from the Virtual International Stroke Trials Archive (VISTA) to calculate heath utility, stratified by modified Rankin Scale (mRS) scores at 3 months [47]. A weighted average was derived using the mRS distribution of stroke survivors collected by the SSNAP [48]. For IHD, a utility decrement was applied to the OSAHS states, accounting for the reduced utility in heart disease patients [46]. Reduced QoL for RTA survivors was estimated by applying a lifetime disutility for RTA, which was sourced from a QoL study [45]

\subsection{Cost-Effectiveness Analyses}

\subsubsection{Base-Case Analysis}

The lifetime cost effectiveness of HNS with Inspire was compared with standard care in the UK by estimating the 
Table 2 Cost inputs and sources

\begin{tabular}{|c|c|c|c|c|c|c|c|c|c|}
\hline & Unit cost & Distribution & Sources & Use $(\%)$ & Distribution & Source & Quantity & Distribution & Source \\
\hline \multicolumn{10}{|c|}{ Health state costs $(2019 £)$} \\
\hline $\begin{array}{l}\text { OSAHS- } \\
\text { severe }\end{array}$ & 1620.50 & $\begin{array}{l}\text { Gamma/ } \\
\text { Cholesky } \\
95 \% \text { CI } \\
1397.3- \\
1843.7\end{array}$ & {$[37]$} & & & & & & \\
\hline OSAHS—mild & 1472.04 & $\begin{array}{l}\text { Gamma/ } \\
\text { Cholesky } \\
95 \% \text { CI } \\
1260.2- \\
1638.8\end{array}$ & {$[37]$} & & & & & & \\
\hline Post-stroke & 6346.44 & $\begin{array}{l}\text { Gamma/ } \\
\text { Cholesky } \\
95 \% \text { CI } \\
5967.2- \\
6725.7)\end{array}$ & [38] & & & & & & \\
\hline Post-IHD & 512.17 & $\begin{array}{l}\text { Gamma/ } \\
\text { Cholesky } \\
\text { 95\% CI } \\
388.7-635.7\end{array}$ & [39] & & & & & & \\
\hline \multicolumn{10}{|c|}{ Event costs $(2019 £)$} \\
\hline $\begin{array}{l}\text { Acute IHD } \\
\text { costs }\end{array}$ & 4088.00 & $\begin{array}{l}\text { Gamma/ } \\
\text { Cholesky } \\
95 \% \text { CI } \\
4007.0- \\
4169.0)\end{array}$ & [39] & & & & & & \\
\hline $\begin{array}{l}\text { Acute stroke } \\
\text { costs }\end{array}$ & $24,414.68$ & $\begin{array}{l}\text { Gamma/ } \\
\text { Cholesky } \\
95 \% \text { CI } \\
22,891.2- \\
25,938.2\end{array}$ & {$[38]$} & & & & & & \\
\hline $\begin{array}{l}\text { Slight/serious } \\
\text { RTA }\end{array}$ & 3241.76 & $\begin{array}{l}\text { Gamma } \\
\mathrm{SE}= \pm 25 \% \text { of } \\
\text { the mean }\end{array}$ & {$[40]$} & & & & & & \\
\hline Fatal RTA & $15,718.71$ & $\begin{array}{l}\text { Gamma } \\
\mathrm{SE}= \pm 25 \% \text { of } \\
\text { the mean }\end{array}$ & & & & & & & \\
\hline \multicolumn{10}{|c|}{ Treatment costs (2019 £ unless otherwise specified) } \\
\hline HNS implant & $17,567.72$ & $\begin{array}{l}\text { Gamma } \\
\mathrm{SE}= \pm 25 \% \text { of } \\
\text { the mean }\end{array}$ & Manufacturer & $100 \%$ & Not varied & Assumption & 1 & Not varied & Assumption \\
\hline $\begin{array}{l}\text { Consultant first } \\
\text { appointment }\end{array}$ & 121 & $\begin{array}{l}\text { Gamma } \\
\mathrm{SE}= \pm 25 \% \text { of } \\
\text { the mean }\end{array}$ & $\begin{array}{l}{[41]} \\
\text { Currency } \\
\text { WF01B/Ser- } \\
\text { vice } 134\end{array}$ & $100 \%$ & Not varied & Assumption & 1 & Not varied & Assumption \\
\hline $\begin{array}{l}\text { Consultant } \\
\text { follow-up }\end{array}$ & 99 & $\begin{array}{l}\text { Gamma } \\
\mathrm{SE}= \pm 25 \% \text { of } \\
\text { the mean }\end{array}$ & $\begin{array}{l}{[41]} \\
\text { Currency } \\
\text { WF01A/Ser- } \\
\text { vice } 134\end{array}$ & $100 \%$ & Not varied & Assumption & 1 & Not varied & Assumption \\
\hline Sleep study & 309 & $\begin{array}{l}\text { Gamma } \\
\mathrm{SE}= \pm 25 \% \text { of } \\
\text { the mean }\end{array}$ & $\begin{array}{l}\text { [41] } \\
\text { Currency } \\
\text { DZ50Z, elec- } \\
\text { tive procedure }\end{array}$ & $100 \%$ & Not varied & Assumption & 2 & Not varied & Assumption \\
\hline
\end{tabular}


Table 2 (continued)

\begin{tabular}{|c|c|c|c|c|c|c|c|c|c|}
\hline & Unit cost & Distribution & Sources & Use (\%) & Distribution & Source & Quantity & Distribution & Source \\
\hline $\begin{array}{l}\text { Hospital costs } \\
\text { (bed-days) }\end{array}$ & 374 & $\begin{array}{l}\text { Gamma } \\
\mathrm{SE}= \pm 25 \% \text { of } \\
\text { the mean }\end{array}$ & $\begin{array}{l}\text { [41] } \\
\text { Currency } \\
\text { DZ18E elec- } \\
\text { tive in patient } \\
\text { excess bed } \\
\text { days }\end{array}$ & $100 \%$ & Not varied & Assumption & 1 & Not varied & Assumption \\
\hline $\begin{array}{l}\text { Theatre costs } \\
\text { (min) }\end{array}$ & 12.92 & $\begin{array}{l}\text { Gamma } \\
\mathrm{SE}= \pm 25 \% \text { of } \\
\text { the mean }\end{array}$ & $\begin{array}{l}{[42]} \\
\text { Costs by speci- } \\
\text { ality in } 2019, \\
\text { respiratory } \\
\text { medicine }\end{array}$ & $100 \%$ & Not varied & Assumption & 146 & Not varied & Assumption \\
\hline $\begin{array}{l}\text { Time in theatre } \\
\text { (mins) }\end{array}$ & 146 & $\begin{array}{l}\text { Log normal } \\
\mathrm{SE}= \pm 25 \% \text { of } \\
\text { the mean }\end{array}$ & [17] & & & & & & \\
\hline $\begin{array}{l}\text { Training (con- } \\
\text { sultant time } \\
\text { per hour) }\end{array}$ & 109 & $\begin{array}{l}\text { Gamma } \\
\mathrm{SE}= \pm 25 \% \text { of } \\
\text { the mean }\end{array}$ & $\begin{array}{l}\text { [43] } \\
\text { Surgical } \\
\text { consultant per } \\
\text { hour }\end{array}$ & $100 \%$ & Not varied & Assumption & 4 & Not varied & Assumption \\
\hline $\begin{array}{l}\text { Surgical revi- } \\
\text { sion rate }\end{array}$ & $0.33 \%$ & $\begin{array}{l}\text { Beta } \\
\text { SE }= \pm 25 \% \text { of } \\
\text { the mean }\end{array}$ & [24] & & & & & & \\
\hline $\begin{array}{l}\text { Battery replace- } \\
\text { ment }\end{array}$ & $\begin{array}{l}70 \% \text { cost of } \\
\text { the initial } \\
\text { surgery }\end{array}$ & $\begin{array}{l}\text { Beta } \\
\text { SE }= \pm 25 \% \text { of } \\
\text { the mean }\end{array}$ & Assumption & & & & & & \\
\hline
\end{tabular}

$C I$ confidence interval, $H N S$ hypoglossal nerve stimulation, IHD ischaemic heart disease, OSAHS obstructive sleep apnoea/hypopnoea syndrome, $R T A$ road traffic accident, $S E$ standard error

expected lifetime costs and QALYs of 10,000 patients using PSA. All model inputs were varied simultaneously, randomly sampling from the distributions reported in Tables 1 , 2 and 3. To account for the relationship between the HRs for severe OSASH and mild OSASH, we sampled from a uniform distribution for the HR for mild OSASH, with a lower bound of 1 and an upper bound tied to sampled HR for severe OSASH. We conducted 10,000 Monte Carlo simulations; point estimates were randomly sampled from probability distributions using a custom visual basic for applications (VBA) script following an approach outlined by Briggs et al. [23]. Uncertainty in the optimal treatment strategy was explored by reporting the probability that HNS with Inspire was the most cost-effective strategy in a costeffectiveness acceptability curve (CEAC) plotted across a range of different willingness-to-pay (WTP) thresholds. We also report the number of fatal and non-fatal strokes and IHD and RTA events for each treatment and the number of events that would be avoided by the most effective treatment.

\subsubsection{Sensitivity Analysis}

One-way sensitivity analysis (OWSA) was performed on all model parameters to investigate the sensitivity of the model result to variations in each of the parameter values. Where CIs were not available, we varied the parameters by $\pm 25 \%$. Four additional scenario analyses were conducted to explore uncertainty in major model assumptions. There is mixed evidence on the effect of CPAP in improving long-term CVD outcomes in OSAHS. A meta-analysis of seven randomised controlled trials [49] analysing the results from 4268 moderate or severe OSAHS patients demonstrated a non-significant, $26 \%$ relative risk reduction in major adverse cardiovascular events with CPAP (RR $0.74,95 \%$ CI $\left.0.47-1.17 ; p=0.19, I^{2}=48 \%\right]$. Similarly, a meta-analysis of clinical trials of CPAP management of OSAHS [50] found no evidence of a benefit in longterm CVD outcomes despite significant improvement in a patient's AHI. It is not clear therefore that the improvements in disease severity offered by treatment of OSAHS will translate to benefits in CVD outcomes. However, subgroup analysis in the meta-analysis by Khan et al. [49] revealed that people with a CPAP adherence time $>\_4 \mathrm{~h} /$ night reduced the risk of major cardiovascular events by $57 \%$ (RR $0.43,95 \%$ CI $0.23-0.80 ; p=0.01, I^{2}=0 \%$ ), leading the authors to conclude CPAP may have a preventative effective where adherence is $>4 \mathrm{~h} / \mathrm{night}$. To test the impact of a lower effect on cardiovascular events, we conducted three scenario analyses, reducing the difference in the HRs of OSAHS between severe and mild disease by half (HR for severe $=2.74$, HR for mild $=1.99$ ). Additionally, because the evidence base underpinning the 
Table 3 Health state utilities

\begin{tabular}{|c|c|c|c|}
\hline & Input & Distribution & Sources \\
\hline \multicolumn{4}{|l|}{ OSAHS health states } \\
\hline OSAHS—severe & 0.765 & $\begin{array}{l}\text { Beta/Cholesky } \\
95 \% \text { CI } 0.756-0.774\end{array}$ & \multirow[t]{2}{*}[44]{} \\
\hline OSAHS—mild & 0.815 & $\begin{array}{l}\text { Beta/Cholesky } \\
\text { 95\% CI 0.803-0.827 }\end{array}$ & \\
\hline \multicolumn{4}{|l|}{ Post-event health states } \\
\hline $\begin{array}{l}\text { Non-fatal RTA (lifetime dis- } \\
\text { counted decrement) }\end{array}$ & 0.036 & $\begin{array}{l}\text { Beta } \\
\text { Range 0.031-0.417 }\end{array}$ & {$[45]$} \\
\hline Post-IHD decrement & 0.0650 & $\begin{array}{l}\text { Beta } \\
95 \% \text { CI } 0.648-0.0652\end{array}$ & [46] \\
\hline \multicolumn{4}{|l|}{ Post-stroke health state utility } \\
\hline mRS 0 & 0.90 & $\begin{array}{l}\text { Beta/Cholesky } \\
95 \% \text { CI 0.886-0.914 }\end{array}$ & \multirow[t]{6}{*}{ [47] } \\
\hline mRS 1 & 0.82 & $\begin{array}{l}\text { Beta/Cholesky } \\
95 \% \text { CI 0.807-0.833 }\end{array}$ & \\
\hline mRS 2 & 0.70 & $\begin{array}{l}\text { Beta/Cholesky } \\
95 \% \text { CI } 0.684-0.716\end{array}$ & \\
\hline mRS 3 & 0.53 & $\begin{array}{l}\text { Beta/Cholesky } \\
95 \% \text { CI } 0.510-0.550\end{array}$ & \\
\hline mRS 4 & 0.20 & $\begin{array}{l}\text { Beta/Cholesky } \\
95 \% \text { CI } 0.179-0.221\end{array}$ & \\
\hline mRS 5 & -0.15 & $\begin{array}{l}\text { Beta/Cholesky } \\
95 \% \text { CI }-0.175 \text { to }-0.125)\end{array}$ & \\
\hline \multicolumn{4}{|c|}{ Post-stroke mRS distribution (\%) } \\
\hline mRS 0 & 18.2 & $\begin{array}{l}\text { Dirichlet } \\
95 \% \text { CI } 17.7-18.7\end{array}$ & \multirow{6}{*}{$\begin{array}{l}\text { [48] (outcomes } \\
\text { at } 6 \text { months, } \\
n=20,213 \text { ) }\end{array}$} \\
\hline mRS 1 & 28.6 & $\begin{array}{l}\text { Dirichlet } \\
\text { 95\% CI 28.0-29.2 }\end{array}$ & \\
\hline mRS 2 & 20.0 & $\begin{array}{l}\text { Dirichlet } \\
\text { 95\% CI 19.4-20.6 }\end{array}$ & \\
\hline mRS 3 & 19.2 & $\begin{array}{l}\text { Dirichlet } \\
\text { 95\% CI 18.7-19.7 }\end{array}$ & \\
\hline mRS 4 & 10.3 & $\begin{array}{l}\text { Dirichlet } \\
\text { 95\% CI 9.9-10.7 }\end{array}$ & \\
\hline mRS 5 & 3.7 & $\begin{array}{l}\text { Dirichlet } \\
95 \% \text { CI } 3.4-4.0\end{array}$ & \\
\hline
\end{tabular}

$C I$ confidence interval, $I H D$ ischaemic heart disease, $m R S$ modified Rankin score, OSAHS obstructive sleep apnoea/hypopnoea syndrome, $R T A$ road traffic accident

increased risk of RTA with uncontrolled OSAHS patients is uncertain, we explored the impact of RTA on the overall cost effectiveness by setting the HR to 1 in combination with the reduced effect on cardiovascular events. A third scenario assumed no reduction in CVD risk with treatment (HR for severe $=2.74$, HR for mild $=2.74)$.

Additionally, the choice of utility difference between HNS patients (mild disease) and standard care (severe disease) is arguably conservative; the values are based on CPAP-adherent patients who were not as symptomatic, as defined by their Epworth Sleepiness Scale (ESS) scores, as those in the STAR trial; we therefore tested a 0.1 difference in utilities between the two treatment arms' OSAHS states that is reflective of the utility gain observed with CPAP use in very severe OSAHS patients in Brazil [51].
Finally, two further areas of uncertainty were explored. In a scenario analysis, the training cost was excluded to reflect costs in a steady state, after the initial adoption phase. An OWSA was also conducted to test the impact of the assumptions applied for the proportion of IHD cases resulting in fatality in the two age bands with missing data. The lower bound applied the rate in the prior age category (37.8\%) and the upper bound matched the case fatality rate to $100 \%$.

Expected value of perfect information (EVPI) and expected value of partial perfect information (EVPPI) analyses were conducted to quantify the value in conducting future research to address uncertainty in the model and specifically to quantify the value of reducing uncertainty regarding the risk of CVD in patients with severe OSASH treated with Inspire. The methods were as described by Oostenbrink 
et al. [52] and Brennan et al. [53] to conduct the EVPI and EVPPI, with further details provided in electronic supplementary material (ESM) 1.

\section{Results}

\subsection{Base-Case Findings}

Cost-effectiveness results are presented in Table 4. Compared with standard care, HNS with Inspire generated higher expected lifetime QALYs (12.72 vs. 11.15) and higher expected treatment-related costs that were partially offset by lower expected lifetime health care costs, resulting in higher overall lifetime costs ( $£ 65,026$ vs. $£ 36,727$ ). This resulted in an incremental cost-effectiveness ratio (ICER) for HNS versus standard care of $£ 17,989$ per QALY. The number of stroke, IHD and RTA events was substantially lower in the HNS arm, with 1498, 798, and 9069 events avoided, respectively.

The results of the base-case PSA shown in the cost-effectiveness plane (CEP) (Fig. 2) illustrate that in most simulations, the ICERs were in the top-right quadrant, where HNS is more expensive and improves outcomes. There were also some simulations where HNS dominated standard care because it was cost-saving and improved outcome. The CEAC (Fig. 2) plots the probability of cost effectiveness against WTP thresholds and shows that HNS has a 45.5\% and $68.7 \%$ probability of being cost effective at a WTP of $£ 20,000$ and $£ 30,000 / Q A L Y$ gained, respectively.

\subsection{Sensitivity and Scenario Analysis Findings}

The results of the OWSA are illustrated in the tornado plot shown in Fig. 3); the top 15 most influential parameters are shown. Only one parameter caused the model to breach a WTP of $£ 30,000 / Q A L Y$, which was the HR for CVD for mild OSAHS. The key model drivers were the CVD HRs for mild and severe OSAHS that influenced both the efficacy and lifetime costs.

Findings from the scenario analyses are presented in Table 4. In the first scenario analysis, the effect of the improvement in the risk of developing CVD with HNS treatment has been reduced by half. This reduces the benefit in life expectancy observed in the HNS arm compared with standard care, which is why the incremental life-years and QALYs are lower compared with the basecase analysis. Overall, in this scenario, the ICER of HNS versus standard care is $£ 25,910$ per QALY. In the second scenario, the difference in HR between severe and mild disease for risk of CVD is reduced by half and the effect on RTA has been removed (setting the HR to 1 in both model arms). As expected, this reduces the life-expectancy gain, and reduces the QALY gain to 1.07 , which is achieved due to the difference in the utility of the severe OSAHS and mild treatment states and a small utility gain from reduced cardiovascular events. The ICER for scenario 2 increases further compared with the base-case analysis, to $£ 28,908$ per QALY. Removing all benefit of reduced risk of CVD increases the ICER to $£ 39,425$ and this scenario can conceivably be considered as an upper bound for the ICER. Finally, in the fourth scenario, a less conservative value for the utility difference between severe and mild OSAHS has been used. In this scenario, the QALY gain is increased compared with the base-case analysis and the ICER is lower at $£ 12,452$ per QALY.

Removing the training costs had minimal impact on the cost-effectiveness result, reducing the ICER slightly to $£ 17,981$. Varying the proportion of IHD cases resulting in fatality for the two missing age brackets also had minimal impact on the cost-effectiveness result, varying the ICER between $£ 18,100$ and $£ 17,947$.

At WTP thresholds of $£ 20,000$ and $£ 30,000$ QALY gained, the EVPI was $£ 18,205$ and $£ 9641$ per patient, respectively. At the same thresholds, the EVPPI for the HRs for CVD in severe (untreated) and mild (treated) OSA were $£ 11,593$ and $£ 2745$ per patient, respectively. In both analyses, the value of removing uncertainty decreases at a higher WTP threshold because there is higher probability that HNS with Inspire is cost effective. Further details are reported in ESM 1.

A conservative estimate of the population that may benefit from HNS with Inspire is 22,275 adults. This was calculated assuming at least 330,000 adults are diagnosed with OSASH in the UK, of which $50 \%$ have mild or severe disease [7], and that of these, approximately $13.5 \%$ are likely to be suitable candidates for HNS with Inspire, as was the experience on clinical trial enrolment [54]. At a WTP threshold of $£ 20,000$ per QALY gained, the population EVPI is $£ 405$ million and the population EVPPI for the HRs for CVD is $£ 258$ million.

\section{Discussion}

Our analysis is the first to assess the cost effectiveness of HNS with Inspire compared with standard care to treat severe OSAHS from an NHS perspective in the UK. The results presented show that HNS has a $45.5 \%$ probability of being cost effective at a WTP set at $£ 20,000$ per QALY, and there is a high likelihood (68.7\%) of cost effectiveness if the WTP is set at $£ 30,000$ per QALY. This has important implications for NHS decision makers and patients with severe OSASH who have tried and have not responded to CPAP and where there are currently no other recommended treatments [11]. 
Table 4 Cost-effectiveness results

\begin{tabular}{|c|c|c|c|}
\hline & HNS & $\mathrm{SC}$ & Difference \\
\hline \multicolumn{4}{|l|}{ Base-case analysis } \\
\hline \multicolumn{4}{|c|}{ Treatment outcomes after 50 years (per cohort, $n=10,000$ ) } \\
\hline IHD events & 2513 & 4010 & -1498 \\
\hline Stroke events & 1799 & 2589 & -789 \\
\hline RTA events & 5503 & 14,572 & -9069 \\
\hline IHD fatalities & 1115 & 1590 & -475 \\
\hline Stroke fatalities & 438 & 575 & -137 \\
\hline RTA fatalities & 14 & 37 & -23 \\
\hline \multicolumn{4}{|c|}{ Costs after 50 years (per patient) } \\
\hline \multicolumn{4}{|c|}{ Health care costs } \\
\hline OSA & $£ 22,046$ & $£ 20,774$ & $£ 1,272$ \\
\hline IHD & $£ 2112$ & $£ 4260$ & $-£ 2148$ \\
\hline Stroke & $£ 4950$ & $£ 8615$ & $-£ 3665$ \\
\hline RTA & $£ 1120$ & $£ 3078$ & $-£ 1959$ \\
\hline \multicolumn{4}{|l|}{ Intervention costs } \\
\hline HNS procedure costs & $£ 34,798$ & $£ 0$ & $£ 34,798$ \\
\hline Total costs & $£ 65,026$ & $£ 36,727$ & $£ 28,299$ \\
\hline \multicolumn{4}{|c|}{ Health outcomes after 50 years (per patient) } \\
\hline Life-years (discounted) & 16.30 & 15.33 & 0.97 \\
\hline QALYs (discounted) & 12.72 & 11.15 & 1.57 \\
\hline ICER after 50 years & & & $£ 17,989$ \\
\hline \multicolumn{4}{|l|}{ Scenario analysis } \\
\hline \multicolumn{4}{|c|}{ 1. Reduced impact of HNS on CVD outcomes } \\
\hline Total costs & $£ 65,683$ & $£ 36,727$ & $£ 28,956$ \\
\hline Life-years (discounted) & 15.77 & 15.33 & 0.44 \\
\hline QALYs (discounted) & 12.27 & 11.15 & 1.12 \\
\hline ICER after 50 years & & & $£ 25,910$ \\
\hline \multicolumn{4}{|c|}{ 2. Reduced impact of HNS on CVD outcomes and no impact on RTAs } \\
\hline Total costs & $£ 65,683$ & $£ 34,742$ & $£ 30,941$ \\
\hline Life-years (discounted) & 15.77 & 15.35 & 0.42 \\
\hline QALYs (discounted) & 12.27 & 11.20 & 1.07 \\
\hline ICER after 50 years & & & $£ 28,908$ \\
\hline \multicolumn{4}{|c|}{ 3. No impact of HNS on CVD outcomes } \\
\hline Total costs & $£ 64,774$ & $£ 34,257$ & $£ 30,517$ \\
\hline Life-years (discounted) & 16.49 & 16.47 & 0.02 \\
\hline QALYs (discounted) & 12.89 & 12.06 & $\mathbf{0 . 8 3}$ \\
\hline Total costs & & & $£ 36,683$ \\
\hline \multicolumn{4}{|c|}{ 4. Increased utility difference between severe and mild disease } \\
\hline Total costs & $£ 65,026$ & $£ 36,727$ & $£ 28,299$ \\
\hline Life-years (discounted) & 16.30 & 15.33 & 0.97 \\
\hline QALYs (discounted) & 12.72 & 10.45 & 2.27 \\
\hline ICER after 50 years & & & $£ 12,452$ \\
\hline
\end{tabular}

$C V D$ cardiovascular disease, HNS hypoglossal nerve stimulation, ICER incremental cost-effectiveness ratio, $I H D$ ischaemic heart disease, $O S A$ obstructive sleep apnoea, $Q A L Y S$ quality-adjusted life-years, $R T A$ road traffic accident, $S C$ standard care 
Fig. 2 Probabilistic sensitivity analysis for base-case analysis of hypoglossal nerve stimulation with Inspire vs. standard care: (top) cost-effectiveness plane; (bottom) cost-effectiveness acceptability curve
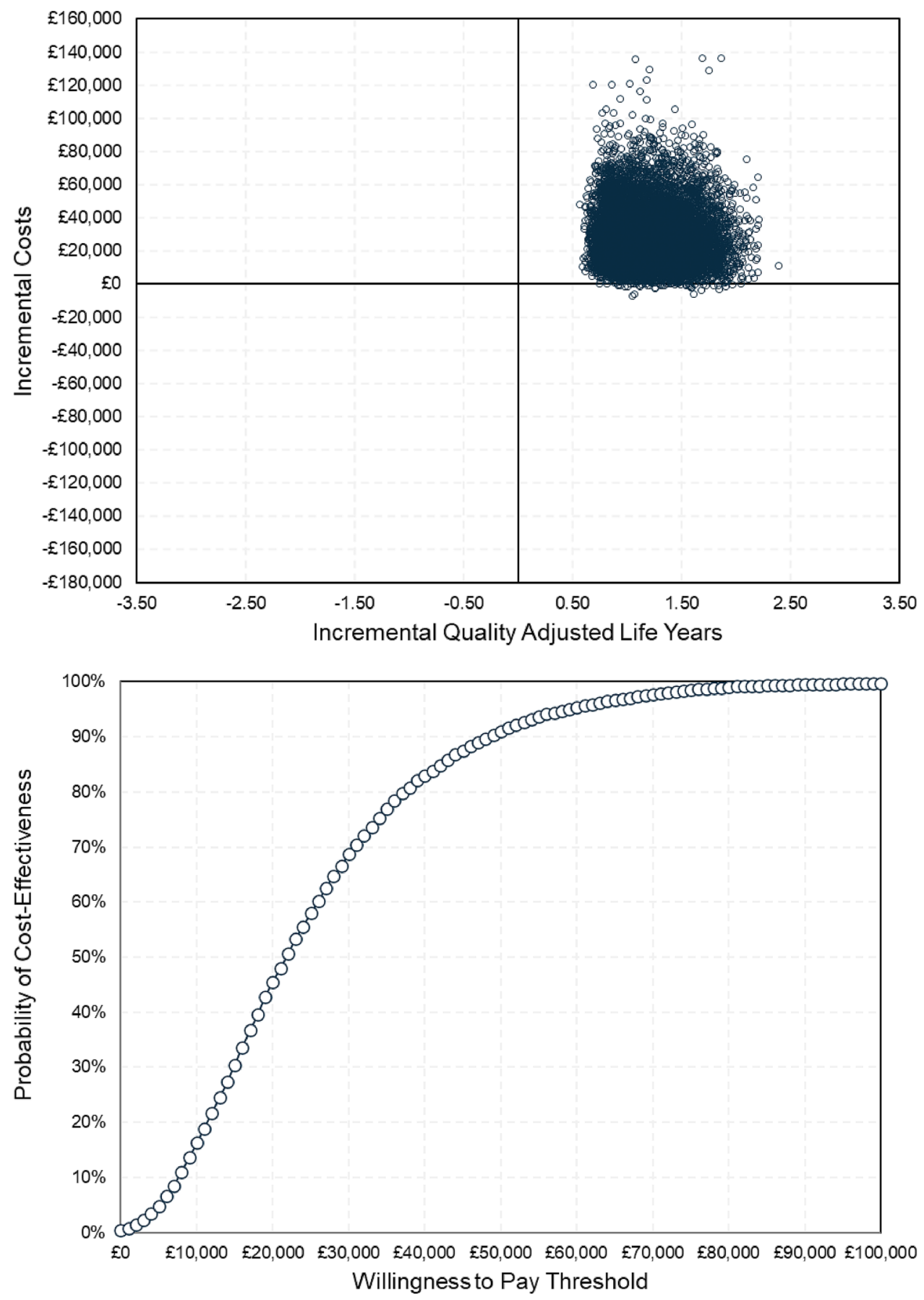

We used a similar modelling framework to other modelling efforts within the therapeutic area [11] reviewed by NICE. However, unlike the York model in TA139, we were able to avoid using Framingham risk equations to estimate the underlying risk of stroke and IHD by utilising large population studies and/or datasets. This is important in a UK context because it has been shown that the Framingham risk equation significantly overpredicts the risk of CVD events in British patients [55]. Our findings are consistent with other economic models conducted from a German [56] and US
[27] payer perspective; incremental ICERs of $€ 44,446$ per QALY gained and \$39,471 per QALY, respectively, were reported. When converted on a purchasing power parity basis, our analysis has lower ICERs than these two prior evaluations, which employed very similar model structures to each other. The difference appears to be largely driven by reduced survival in these models, which might be explained by the inclusion of a hypertensive health state prior to IHD and stroke. 


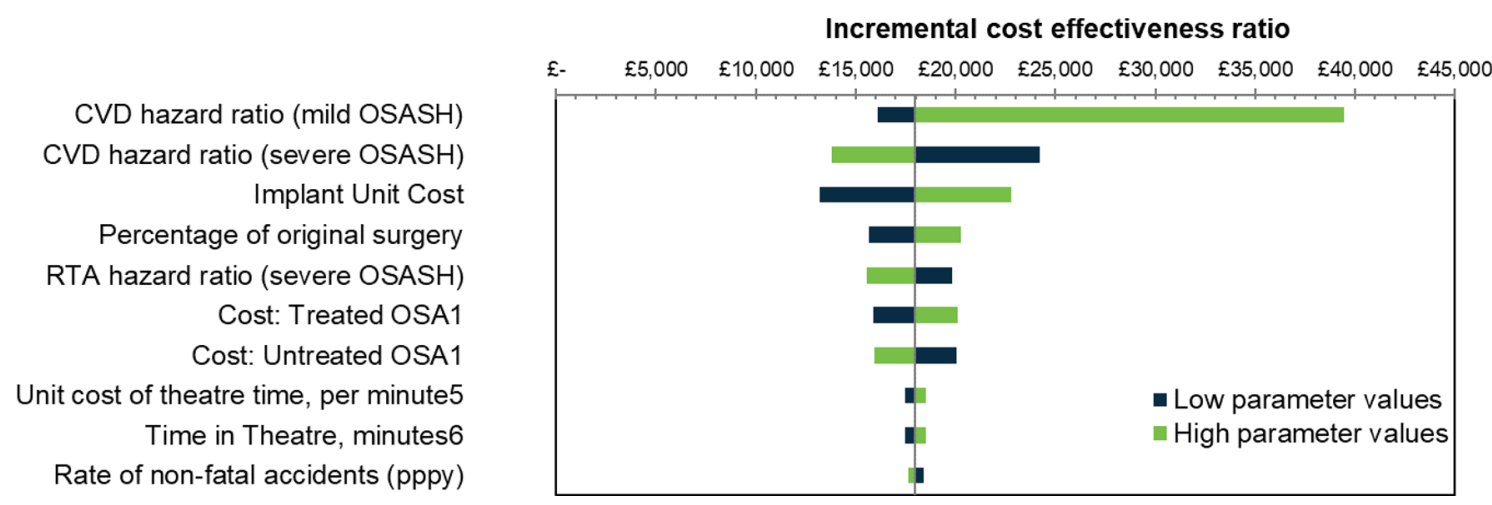

Fig. 3 One-way sensitivity analysis of hypoglossal nerve stimulation with Inspire versus standard care. CVD cardiovascular disease, OSASH obstructive sleep apnoea/hypopnoea syndrome, $R T A$ road traffic accident, pppy per person per year

There are several limitations to our analysis. We used the reduction in AHI observed in the HNS clinical trials and real-world evidence $[17,24,35]$ as a surrogate marker for a reduction in the risk of CVD and RTAs. In terms of CVD, this assumption is open to criticism based on the results of a meta-analysis that failed to show an effect on CVD of CPAP use in OSAHS patients despite a mean reduction in AHI [50]. This finding remains a contentious issue and there are a number of reasons to suggest that it may not be generalisable to HNS therapy: (1) the adherence rates of CPAP in the included studies ranged between 1.4 and $6.6 \mathrm{~h} /$ day, compared with an average adherence to HNS of $5.6 \mathrm{~h} /$ day reported in a large real-world study [19]. It is therefore possible that the benefit of treatment is only preserved when adherence rates are higher. This theory is supported by a meta-analysis [49] that concluded CPAP therapy may reduce major adverse cardiovascular events among subjects with CPAP time exceeding $4 \mathrm{~h} / \mathrm{night}$; (2) the inclusion criteria of many of the studies meant only patients with prior CVD were involved, therefore the studies are strictly only representative of secondary CVD prevention and not primary CVD prevention, which could lead to different effects, as demonstrated in observational studies [57]; and (3) there is an ethical problem with assigning severely symptomatic patients to sham therapy; therefore, these trials often exclude the more severely affected patients and hence it may be that the effects of CPAP on vascular outcomes are restricted to patients with more severe symptomatology. Our analysis examined the effect of reducing the benefit of AHI reduction by $50 \%$, and although the deterministic ICER increased to $£ 25,910$ per QALY, this would be considered cost effective when using a WTP threshold of $£ 30,000$ per QALY. When this benefit is completely removed, assuming no reduction in CVD risk with treatment, the ICER increases to $£ 39,425$, which is considered an upper bound for cost effectiveness. The EVPI and EVPPI analysis suggest there is high value in conducting further research to remove these areas of uncertainty; however, this value is reduced at the higher WTP threshold of $£ 30,000$, where there is a higher probability that the intervention is cost effective.

Finally, the expected lifetime QALYs are largely dependent on the choice of utility value used for the OSAHS health states. In our base-case, due to a lack of directly elicited utility values from HNS clinical trials, we have used a utility score based on the pre-CPAP and post-CPAP EQ-5D score of US OSAHS patients adherent to CPAP therapy [44]; however, it is not certain that this population is fully representative of the potential utility improvements that might be made with HNS therapy. The study population had relatively low $(<10)$ ESS scores at baseline, therefore it is conceivable that more symptomatic patients would experience greater improvement. Indeed, a greater improvement was shown in an observational CPAP study that showed utility improvement of 0.092 QALY, and although the study included fewer patients and was based in Brazil, the baseline ESS score was closer to that seen in the HNS trials [51]. In addition, clinical trials [17] and real-world evidence [19, 22, 24] on HNS demonstrated larger magnitudes of QoL improvements than usually observed with CPAP. Our scenario analysis testing this finding showed that there was a high likelihood of cost effectiveness.

The generalisability of our findings to other geographies is limited. We have taken an NHS and social care perspective and as per HTA guidance in the UK, we have restricted our analysis to exclude a societal perspective. Therefore, the indirect costs incurred by the patient and/or society as a result of lost productivity are not captured. Taking such costs into account would likely increase the cost effectiveness of HNS compared with standard care, because increased work productivity in the HNS arm would reduce incremental costs compared with standard care. Priorities for future research should include verifying the impact of untreated OSA on the risk of CVD and RTA events in populations with severe 
OSAHS. Additionally, further areas for research should prioritise the capture of high-quality utility values (e.g. EQ-5D) for people with untreated OSA who have previously not responded to CPAP and are subsequently treated with HNS. The collection of absenteeism and presenteeism data in this population would allow for the analysis to be conducted from a societal perspective. Disutility associated with adherence to CPAP where it is common for patients to experience persistent discomfort is also warranted.

\section{Conclusion}

Over a patient's lifetime, HNS with Inspire may be expected to be cost effective when compared with no treatment in patients with severe OSAHS who have tried and have not responded to CPAP from an NHS perspective, assuming battery replacement every 11 years.

Supplementary Information The online version contains supplementary material available at https://doi.org/10.1007/s41669-021-00266-7.

Acknowledgements JS's contribution was partially supported by the National Institute for Health Research (NIHR) Biomedical Research Centre based at Guy's and St Thomas' NHS Foundation Trust and King's College London. The views expressed are those of the authors and not necessarily those of the NHS, the NIHR or the Department of Health.

\section{Declarations}

Funding This study was funded by Inspire Medical Systems.

Conflict of interest Deirdre Blissett and Rob Blissett are managing directors of MedTech Economics, a health economic consultancy that was commissioned by Inspire Medical Systems to develop the economic model described in this manuscript. Joerg Steier is a named inventor on a patent to treat sleep apnoea using transcutaneous stimulation: Apparatus for Treatment of Snoring and Sleep Apnoea (WO2016124739A1). Karagama Yakubu has no conflicts of interest to declare.

Ethics approval Not applicable.

Consent to participate Not applicable.

Consent for publication Not applicable

Availability of data and materials All data applied in the model are reported in the manuscript. The model code may be requested from the corresponding author (DB) upon reasonable request.

Author contributions DB and RB conceived the presented idea. DB and RB developed and performed the analysis. DB, RB JS and YK verified the analytical methods. $\mathrm{DB}$ and $\mathrm{RB}$ took the lead in writing the manuscript. All authors provided critical feedback and helped shape the research, analysis and manuscript.
Open Access This article is licensed under a Creative Commons Attribution-NonCommercial 4.0 International License, which permits any non-commercial use, sharing, adaptation, distribution and reproduction in any medium or format, as long as you give appropriate credit to the original author(s) and the source, provide a link to the Creative Commons licence, and indicate if changes were made. The images or other third party material in this article are included in the article's Creative Commons licence, unless indicated otherwise in a credit line to the material. If material is not included in the article's Creative Commons licence and your intended use is not permitted by statutory regulation or exceeds the permitted use, you will need to obtain permission directly from the copyright holder. To view a copy of this licence, visit http://creativecommons.org/licenses/by-nc/4.0/.

\section{References}

1. Peppard PE, et al. Increased prevalence of sleep-disordered breathing in adults. J Am J Epidemiol. 2013;177(9):1006-14.

2. Mannarino MR, Di Filippo F, Pirro M. Obstructive sleep apnea syndrome. J Eur J Intern Med. 2012;23(7):586-93.

3. Dutt N, et al. Quality of life impairment in patients of obstructive sleep apnea and its relation with the severity of disease. J Lung India. 2013;30(4):289.

4. Bjornsdottir E, et al. Quality of life among untreated sleep apnea patients compared with the general population and changes after treatment with positive airway pressure. J Sleep Res. 2015;24(3):328-38.

5. Lacasse Y, Godbout C, Sériès F. Health-related quality of life in obstructive sleep apnoea. J Eur Respir. 2002;19(3):499-503.

6. Pengo $\mathrm{M}$, et al. Blood pressure effects of obstructive sleep apnea treatment by continuous positive airway pressure: systematic review, metaanalysis and evaluation of phenotypes predicting response. Eur Respir J. 2019;54(Suppl):63.

7. Rejón-Parrilla JC, Garau M, Sussex J. Obstructive sleep apnoea: health economics report. London: British Lung Foundation, Office of Health Economics; 2014.

8. Guest JF, et al. Cost-effectiveness of using continuous positive airway pressure in the treatment of severe obstructive sleep apnoea/hypopnoea syndrome in the UK. J Thorax. 2008;63(10):860-5.

9. George CF. Reduction in motor vehicle collisions following treatment of sleep apnoea with nasal CPAP. J Thorax. 2001;56(7):508-12.

10. Walter RJ, Hagedorn SI, Lettieri CJ. Impact of diagnosing and treating obstructive sleep apnea on healthcare utilization. J Sleep Med. 2017;38:73-7.

11. Continuous positive airway pressure for the treatment of obstructive sleep apnoea/hypopnoea syndrome. Technology appraisal guidance [TA139]. London: National Institute of Health and Care Excellence; 2008.

12. Rotenberg BW, Murariu D, Pang KP. Trends in CPAP adherence over twenty years of data collection: a flattened curve. J Otolaryngol Head Neck Surg. 2016;45(1):43.

13. Weaver TE, Grunstein RR. Adherence to continuous positive airway pressure therapy: the challenge to effective treatment. J Proc Am Thorac Soc. 2008;5(2):173-8.

14. Ishak A, et al. BPAP is an effective second-line therapy for obese patients with OSA failing regular CPAP: a prospective observational cohort study. J Respirol. 2020;25(4):443-8.

15. Woodson BT, et al. Upper airway stimulation for obstructive sleep apnea: 5-year outcomes. J Otolaryngol Head Neck Surg. 2018;159(1):194-202. 
16. Baptista PM, et al. Hypoglossal nerve stimulation in the treatment of obstructive sleep apnea: patient selection and new perspectives. J Nat Sci Sleep. 2020;12:151.

17. Strollo PJ Jr, et al. Upper-airway stimulation for obstructive sleep apnea. J New Engl J Med. 2014;370(2):139-49.

18. Heiser $\mathrm{C}$, et al. Outcomes of upper airway stimulation for obstructive sleep apnea in a multicenter German postmarket study. J Otolaryngol Head. 2017;156(2):378-84.

19. Mehra R, et al. Upper airway stimulation versus untreated comparators in positive airway pressure treatment refractory obstructive sleep apnea. Ann Am Thorac Soc. 2020;17(12):161-1619.

20. Shah J, et al. Uvulopalatopharyngoplasty vs CN XII stimulation for treatment of obstructive sleep apnea: a single institution experience. J Am J Otolaryngol. 2018;39(3):266-70.

21. Huntley $\mathrm{C}$, et al. Upper airway stimulation for treatment of obstructive sleep apnea: an evaluation and comparison of outcomes at two academic centers. J Clin Sleep Med. 2017;13(09):1075-9.

22. Withrow K, et al. Upper airway stimulation response in older adults with moderate to severe obstructive sleep apnea. J Otolaryngol Head Neck Surg. 2019;161(4):714-9.

23. Briggs A, Sculpher M, Claxton K. Decision modelling for health economic evaluation. Oup Oxford; 2006.

24. Boon M, et al. Upper airway stimulation for obstructive sleep apnea: results from the ADHERE registry. J Otolaryngol Head Neck Surg. 2018;159(2):379-85.

25. McDaid C, et al. Continuous positive airway pressure devices for the treatment of obstructive sleep apnoea-hypopnoea syndrome: a systematic review and economic analysis. NIHR Health Technology Assessment programme: Executive Summaries; 2009.

26. Sharples LD, et al. Meta-analysis of randomised controlled trials of oral mandibular advancement devices and continuous positive airway pressure for obstructive sleep apnoea-hypopnoea. J Sleep Med Rev. 2016;27:108-24.

27. Pietzsch JB, et al. Long-term cost-effectiveness of upper airway stimulation for the treatment of obstructive sleep apnea: a model-based projection based on the STAR trial. J Sleep. 2015;38(5):735-44.

28. Fu Y, et al. Meta-analysis of all-cause and cardiovascular mortality in obstructive sleep apnea with or without continuous positive airway pressure treatment. Sleep Breath. 2017;21(1):181-9.

29. Leger D, Stepnowsky C. The economic and societal burden of excessive daytime sleepiness in patients with obstructive sleep apnea. J Sleep Med Rev. 2020;51:101275.

30. Seminog OO, et al. Determinants of the decline in mortality from acute stroke in England: linked national database study of 795869 adults. BMJ. 2019;365:11778.

31. British Heart Foundation. Heart \& Circulatory Disease Statistics 2020. https://www.bhf.org.uk/what-we-do/our-research/heart-stati stics/heart-statistics-publications/cardiovascular-disease-statistics2020. Accessed 17 Sept 2020.

32. Reported road casualties in Great Britain: 2018 annual report. Statistical Release. Department of Transport; 2019.

33. RAC Foundation. Motoring FAQS. https://www.racfoundation. org/motoring-faqs/mobility\#a15. Accessed 17 Sept 2020.

34. Department for Transport. Estimates of the annual non-fatal road casualties in Great Britain, NTS compared to STATS19. 2019. https://www.gov.uk/government/statistical-data-sets/ras54-surveydata. Accessed 17 Sept 2019.

35. Steffen A, et al. Long-term follow-up of the German post-market study for upper airway stimulation for obstructive sleep apnea. Sleep Breath. 2020;24(3):979-84.

36. Chiang CL, World Health Organization. Life table and mortality analysis. World health Organization; 1979.
37. McMillan A, et al. A multicentre randomised controlled trial and economic evaluation of continuous positive airway pressure for the treatment of obstructive sleep apnoea syndrome in older people: PREDICT. J Health Technol Assess. 2015;19(40):1.

38. Sentinel Stroke National Audit Programme, Cost and Cost-Effectiveness Analysis, Technical Report. National Guideline Centre and Sentinel Stroke National Audit Programme; 2016, Commissioned by NHS England.

39. Danese MD, et al. Estimating the economic burden of cardiovascular events in patients receiving lipid-modifying therapy in the UK. BMJ Open. 2016;6(8):e011805.

40. Department of Transport. Statistics. Average value of prevention per reported casualty and per reported road accident. Department of Transport, UK; 2018.

41. National Schedule of NHS Costs. London: NHS; 2019.

42. Theatre costs, detailed tables, I. Edinburgh; National Services Scotland; 2019.

43. Curtis L, Burns A. Unit Costs of Health and Social Care 2019. University of Kent. Canterbury: Personal Social Services Research Unit; 2019.

44. Walia HK, et al. Impact of sleep-disordered breathing treatment on quality of life measures in a large clinic-based cohort. J Clin Sleep Med. 2017;13(11):1255.

45. Nyman JA, Barleen NA, Kirdruang P. Quality-adjusted life years lost from nonfatal motor vehicle accident injuries. J Med Decis Mak. 2008;28(6):819-28.

46. Sullivan PW, Ghushchyan V. Preference-based EQ-5D index scores for chronic conditions in the United States. Med Decis Mak. 2006;26(4):410-20.

47. Ali M, et al. Dependency and health utilities in stroke: Data to inform cost-effectiveness analyses. Eur Stroke J. 2017;2(1):70-6.

48. Annual Results Portfolio. Kings College London. London: Sentinel Stroke National Audit Programme; 2019.

49. Khan SU, et al. A meta-analysis of continuous positive airway pressure therapy in prevention of cardiovascular events in patients with obstructive sleep apnoea. J Eur Heart J. 2018;39(24):2291-7.

50. Yu J, et al. Association of positive airway pressure with cardiovascular events and death in adults with sleep apnea: a systematic review and meta-analysis. JAMA. 2017;318(2):156-66.

51. Rizzi CF, et al. Quality-adjusted life-years gain and health status in patients with OSAS after one year of continuous positive airway pressure use. Sleep. 2014;37(12):1963-8.

52. Oostenbrink JB, et al. Expected value of perfect information: an empirical example of reducing decision uncertainty by conducting additional research. J Value Health. 2008;11(7):1070-80.

53. Brennan A, et al. Calculating partial expected value of perfect information via Monte Carlo sampling algorithms. J Med Decis Mak. 2007;27(4):448-70.

54. Soose RJ, et al. OSA treatment history in an upper airway stimulation trial cohort. J World J Otorhinolaryngol Head Neck Surg. 2017;3(2):79-84.

55. Brindle $\mathrm{P}$, et al. Predictive accuracy of the Framingham coronary risk score in British men: prospective cohort study. BMJ. 2003;327(7426):1267.

56. Pietzsch JB, et al. Clinical and economic benefits of upper airway stimulation for obstructive sleep apnea in a European setting. $\mathrm{J}$ Respir. 2019;98(1):38-47.

57. Marin JM, et al. Long-term cardiovascular outcomes in men with obstructive sleep apnoea-hypopnoea with or without treatment with continuous positive airway pressure: an observational study. Lancet. 2005;365(9464):1046-53. 